\title{
EMPODERAMENTO E COMPETÊNCIAS INDIVIDUAIS E GRUPAIS: a criação de ambiente organizacional favorável à inovação
}

\author{
Letícia Rodrigues da FONSECA ${ }^{1}$ \\ Marcelo Ribeiro SILVA ${ }^{2}$ \\ Liliane Dolores FAGUNDES ${ }^{3}$ \\ Janilton Gabiel de SOUZA ${ }^{4}$ \\ Sheldon William SILVA ${ }^{5}$
}

\begin{abstract}
${ }^{1}$ Doutora em Administração pela Universidade Presbiteriana (UPM). Professora na Universidade Vale do Rio Verde (UNINCOR). leticia.rodrigues.vga @ gmail.com

${ }^{2}$ Doutor em Administração pela Universidade Presbiteriana Mackenzie (UPM). Professor na Universidade Federal do Mato Grosso do Sul (UFMS).

${ }^{3}$ Mestra em Engenharia de Produção pela Universidade Federal de Itajubá (UNIFEI). Professora na Universidade Federal do Alfenas (UNIFAL).

${ }^{4}$ Mestre em Psicologia pela Universidade Federal de São João Del-Rey (UFSJ)

${ }^{5}$ Mestre em Administração pela Faculdade Pedro Leopoldo. Professor no Centro Universitário do Sul de Minas.
\end{abstract}

Recebido em: 11/01/2016 - Aprovado em: 29/07/2016 - Disponibilizado em: 30/07/2016

\begin{abstract}
RESUMO
O presente artigo busca compreender como alguns pressupostos subjacentes ao Empoderamento, tais como o Autodesenvolvimento, a Prática Reflexiva e a Aprendizagem Experencial, identificados a partir de referencial teórico, podem ser positivos ao processo de desenvolvimento de competências individuais e grupais sob o ponto de vista da criação de um ambiente organizacional favorável à inovação. Metodologicamente, o presente estudo pode ser classificado como uma análise exploratória descritiva por meio de um estudo de caso singular e de natureza qualitativa. Já a técnica de coleta de dados foi por meio de entrevistas pessoais, utilização de questionário semi-estruturado e observação não-participante. O questionário semi-estruturado foi constituído por questões abertas, previamente selecionadas, cujas respostas tomaram forma a partir do ponto de vista do entrevistado. As observações tiveram como principal objetivo analisar os processos de Autodesenvolvimento, Aprendizagem Experencial e Prática Reflexiva e sua relação com os desafios inerentes à manufatura e à prestação de serviços no âmbito do trabalho. Os resultados obtidos demonstraram que o os pressupostos subjacentes ao Empoderamento são importantes fatores para o desenvolvimento de competências de grupos autônomos, principalmente quando relacionados à inovação dos processos produtivos industriais, sendo esse um diferencial da empresa, passível de sua manutenção e sua sobrevivência no competitivo mercado automotivo brasileiro e internacional.
\end{abstract}

Palavras-chave: Empoderamento. Autodesenvolvimento Prática Reflexiva. Aprendizagem Experencial.

\section{EMPOWERMENT AND INDIVIDUAL AND GROUP COMPETENCES: the}

\section{creation of an organizational environment favorable to innovation}

\begin{abstract}
This article seeks to understand how some assumptions underlying Empowerment, such as Self-development, Reflective Practice and Experiential Learning, identified from a theoretical framework, can be positive to the process of developing individual and group competencies from the point of view of Creation of an organizational environment favorable to innovation. Methodologically, the present study can be classified as a descriptive exploratory analysis by means of a singular case study and qualitative nature. The technique of data collection was through personal interviews, use of a semi-structured questionnaire and non-participant observation. The semi-structured questionnaire was composed of open questions, previously selected, whose answers took shape from the interviewee's point of view. The main objective of the observations was to analyze the processes of Self-development, Experiential Learning and


Reflective Practice and its relation with the inherent challenges of manufacturing and service delivery in the scope of work. The results showed that the assumptions underlying Empowerment are important factors for the development of autonomous group competences, especially when related to the innovation of the industrial production processes, being this a differential of the company, which can be maintained and survived in the competitive market Automotive industry in Brazil and abroad.

Keywords: Generation Y. Motivational vectors. Genos Employee Motivation Assessment Model. Generational groups. Motivation at work.

\section{INTRODUÇÃO}

Com o passar do tempo, a maneira de gerir pessoas sofreu grandes transformações, como por exemplo, a busca por um perfil profissional mais autônomo e empreendedor em relação aquele obediente e disciplinado exigido pelos sistemas formais de gestão. Para satisfazer tais necessidades, as organizações buscaram adequar seus modelos de gestão e desenvolvimento de competências, adequando-os a esta nova realidade (DUTRA, 2001).

O Empoderamento - capacidade de proporcionar, por meio da reflexão, mais poderes ao indivíduo no contexto organizacional, vem sendo discutido como um importante meio de se desenvolver as competências que satisfaçam as atuais necessidades organizacionais (GHAYE, 2001). Acredita-se, pois, que a reflexão seja essencial para o aprendizado e, principalmente, para o desenvolvimento do conhecimento prático. $\mathrm{O}$ Empoderamento não está apenas associado ao desenvolvimento profissional individual, mas também ao coletivo, à responsabilidade, ao controle pessoal e à autodeterminação. Trata-se da conexão entre a reflexão e a ação competente.
Portanto, diante deste cenário, o presente artigo busca compreender como alguns pressupostos subjacentes ao Empoderamento, tais como o Autodesenvolvimento, a Prática Reflexiva e a aprendizagem experencial, identificados a partir de referencial teórico, podem ser positivos no desenvolvimento de competências individuais e grupais sob o ponto de vista da criação de um ambiente organizacional favorável à inovação de produtos e serviços.

Para isso, realizou-se uma análise exploratória descritiva em uma empresa multinacional do segmento automotivo. A escolha por esta organização foi devida ao fato da referida primar pela autonomia de seus colaboradores, estimulando seu Autodesenvolvimento por meio de grupos multidisciplinares de desenvolvimento de produtos e atendimento ao cliente. Espera-se ao final obter informações que demonstrem de que forma o Empoderamento, por meio de seus pressupostos subjacentes, são positivos ao processo de desenvolvimento de competências, capazes de responder aos desafios inerentes das atividades nas situações de trabalho. 


\section{REFERENCIAL TEÓRICO}

\subsection{Gestão de Competências}

Como exposto anteriormente, maneira de gerir pessoas sofreu importantes transformações. De acordo com Dutra (2001), podemos citar como principais mudanças: (1) alteração no perfil das pessoas exigido pelas empresas: em vez de um perfil obediente e disciplinado prefere-se um perfil autônomo e empreendedor; (2) deslocamento do foco da gestão de pessoas por meio do controle, para o foco por meio do desenvolvimento: a marca dos sistemas tradicionais de gestão é o controle. Para estes sistemas os indivíduos são controláveis e devem apresentar uma postura passiva. Atualmente existe uma grande pressão para que a gestão de pessoas seja orientada para a ideia de desenvolvimento mútuo; (3) maior participação das pessoas no sucesso do negócio ou da empresa: as pessoas são vistas como depositárias do patrimônio intelectual da empresa, bem como da capacidade e da agilidade de resposta da organização aos estímulos do ambiente e, ainda, da capacidade de visualização e exploração de oportunidades de negócios.

No entanto, todas essas transformações não foram acompanhadas por completo pelos conceitos e ferramentas que apóiam a gestão por competências. A maneira de gerir pessoas adotada por muitas empresas não conseguiu acompanhar esta realidade.
Uma solução encontrada para se resolver este problema foi adequar o sistema formal de gestão conforme esta realidade. Existe um processo de troca de competências contínuo entre pessoas e organização. A empresa transfere seu patrimônio para as pessoas, aprimorando-as, preparando-as para enfrentar novas situações profissionais como pessoais, dentro ou fora da organização. Já as pessoas ao desenvolverem sua capacidade individual irão transferir para a organização seu aprendizado, oferecendo condições para que esta possa enfrentar novos desafios (DUTRA, 2001).

Portanto, existe uma relação íntima entre as competências organizacionais e as individuais. $\mathrm{O}$ estabelecimento das competências individuais deve estar vinculado à reflexão sobre as competências organizacionais, uma vez que há uma influência mútua entre elas.

Para Carbone et al, (2006), as competências humanas são reveladas no momento em que as pessoas agem durante as situações profissionais com as quais se deparam e servem como ligação entre as condutas individuais e as estratégias da organização. Assim, agregam valor econômico e valor social a indivíduos e organizações, na medida em que contribuem para a consecução de objetivos organizacionais e expressam o reconhecimento social sobre a capacidade das pessoas. 
Sendo a competência compreendida como um conjunto de conhecimentos, habilidades e atitudes, para que a pessoa possa desenvolver suas atribuições e responsabilidades, este conceito tem se mostrado pouco instrumental, pois mesmo que o indivíduo possua os CHA's, estes não garantem que a organização obterá benefício diretamente. Para isso é necessário que este indivíduo possua a capacidade de "entrega" (DUTRA, 2001).

$\mathrm{O}$ indivíduo deve ser avaliado pelo que ele entrega para a organização e não apenas pelo que ele faz conforme determinado pelos sistemas formais de gestão. Por exemplo, dois funcionários que possuem o mesmo cargo com as mesmas atribuições e responsabilidades podem executar a mesma função, no entanto, um poderá executar de maneira mais eficaz em relação ao outro. O indivíduo que atua de maneira mais eficaz é aquele que possui maior capacidade de entrega para a organização.

\subsection{Empoderamento}

De forma crescente, as organizações procuram, através de sofisticado sistema de desenvolvimento de recursos humanos e estratégias de aprendizagem no local de trabalho, desenvolver competências que permitam aos indivíduos aprimorar a capacidade de produzir respostas rápidas e flexíveis ao competitivo ambiente organizacional. A necessidade de flexibilidade resulta num amplo uso de abordagens de competências que servirão como base para provisão da força de trabalho organizacional (LEI; HITT, 1996; SPANGENBERG ET AL, 1999).

A partir desse ponto, as organizações criam formas de conduzir sua força de trabalho de maneira que ela possa ser mais independente, possuidora de autocontrole, pronta para tomar suas próprias decisões e de assumir riscos. A questão do Empoderamento pode ser citada como uma importante abordagem de competências - definida como um movimento de tomada de decisões conferido aos menores níveis organizacionais (FULLAN, et al, 1998, p. 254).

Diante desse cenário, os autores do presente trabalho acreditam que existam pressupostos subjacentes ao Empoderamento: (1) Autodesenvolvimento; (2) Aprendizagem Experencial (3) e Prática Reflexiva.

De acordo com Pedler (1988), no contexto do gerenciamento da educação, o Autodesenvolvimento é um termo pertencente a diversas abordagens no qual se dá o controle ao aprendiz em relação aos processos e tarefas de seu próprio desenvolvimento feito sem a intervenção de um treinador. É o aprendiz que toma as decisões relacionadas aos objetivos escolhendo métodos, significados, o momento e o local para a aprendizagem. Sob a perspectiva do gerenciamento da educação, o Autodesenvolvimento é um importante pilar 
de sustento do Empoderamento, pois o poder nas tomadas de decisões, tanto no âmbito individual quanto grupal, se restringe à melhor forma de aprender. Suas implicações refletirão nas tomadas de decisão vivenciadas dentro do ambiente de trabalho que influenciam nos processos organizacionais e favorecem a autonomia dos indivíduos.

O Empoderamento promove a Prática Reflexiva. Para James e Clarke (1994) apud Ghaye (2001), a reflexão é parte integrante do aprendizado por experiência e do desenvolvimento de conhecimento prático. Reflexão é baseada num entendimento crescente das formas de conhecimento prático e do aprendizado por experiência. A reflexão é central em muitas teorias de aprendizado experencial (Kolb, 1984).

Métodos como aprendizado de ação e aprendizado autogerenciado enfatiza a interação entre interior e o exterior do indivíduo. $\mathrm{O}$ interior é a aquisição de habilidades comunicativas - que são ao mesmo tempo escolhas internas que promovem a transformação. $\mathrm{O}$ exterior é a ação, refere-se à mudança de comportamento aplicada ao desempenho de determinada tarefa e aos resultados advindos dessa transformação. Nessa discussão, por meio da Prática Reflexiva, o Autodesenvolvimento cumpriu um clico e passou a ser tornar uma síntese das ideias interiores onde o desenvolvimento envolve uma passagem contínua de ações exteriores (experiência) para processos interiores (reflexão) e volta para a ação e assim por diante

(PEDLER, 1998, p. 20).

Nessa perspectiva, a definição de Autodesenvolvimento de Pedler, de certa forma, alinha-se à definição de Empoderamento de Freire (1992). Embora a palavra Empowerment já existisse na Língua Inglesa significando "dar poder" a alguém para realizar uma determinada tarefa sem precisar da permissão de outrem, o conceito de Empoderamento de Paulo Freire segue uma lógica diferente. De acordo com o educador, a pessoa, grupo ou instituição empoderada é aquela que realiza por si mesma as mudanças e ações que a levam a evoluir e se fortalecer. Segundo o autor, o Empoderamento não é um movimento que ocorre de fora para dentro, mas internamente, pela conquista da autonomia.

O terceiro pressuposto favorável ao Empoderamento é a Aprendizagem Experencial. Para a teoria da Aprendizagem Experiencial proposta por David Kolb, o conhecimento é o resultado da transformação de experiências que são captadas pela sensação ou pela conceituação, em uma situação onde essas são vivenciadas, refletidas, significadas e reaplicadas, por meio da reflexão ou da ação, em um processo contínuo. De acordo com Kolb (1984), na Aprendizagem Experiencial, há, primeiramente, uma aquisição da informação, 
habilidade ou experiência. Esse estímulo externo e o repertório interno do indivíduo interagem e direcionam a aprendizagem para outro momento, quando há uma especialização do conhecimento. As informações são adaptadas conforme as necessidades e interesses da pessoa, para ocorrer à comparação do novo com o velho efetivando-se a aprendizagem.

Numa outra perspectiva mais pragmática, o Empoderamento pode ser definido como "um processo de reforço dos sentimentos de autoeficácia entre os membros das organizações, por meio da identificação das condições de impotência e sua remoção promovida tanto pelas práticas organizacionais formais, quanto por técnicas informais capazes de fomentar a eficácia da informação" (CONGER; KANUNGO, 1988).

A definição dos autores gera um sentido ambíguo, pois a questão da informalidade é trazida por "técnicas", levando a crer que mesmo nas situações informais de tomadas de decisões, a organização procura manter-se no controle por meio de uso de técnicas ou tentativas de racionalização da informalidade.

Thomas e Velthouse (1990) vão além, desenvolvendo uma abordagem geral para o Empoderamento a partir das definições de Conger e Kanungo. Os autores argumentam que o Empoderamento é uma abordagem multifacetada, definindo-o de forma mais ampla como "aumento da motivação (tarefa) intrínseca" manifestada em um conjunto de quatro cognições que refletem a orientação de um indivíduo ao seu papel na execução do trabalho: competência, impacto, significado e escolha (SPREITZER, 1995). O impacto é visto como "fazer a diferença" em termos de realização do objetivo da tarefa; competência é a capacidade de um indivíduo para desempenhar atividades habilmente; o significado é o valor do objetivo da tarefa ou finalidade, julgada em relação aos ideais do próprio indivíduo ou normas; enquanto a escolha é a "responsabilidade causal para as ações de uma pessoa" (THOMAS; VELTHOUSE, 1990).

\section{ASPECTOS METODOLÓGICOS}

Do ponto de vista metodológico, o presente estudo pode ser classificado como uma análise exploratória descritiva por meio de um estudo de caso singular e de natureza qualitativa. Segundo Mintzberg (1997), o método de estudo de caso é altamente recomendável para a construção de modelos de análise de mudanças estratégicas organizacionais.

O estudo de caso é considerado um tipo de análise qualitativa e que, segundo Laville e Dione (1999), é uma investigação que permite fornecer explicações no que tange diretamente ao caso considerado e aos elementos que marcam o contexto. A vantagem dessa estratégia é a possibilidade de aprofundamento que esta oferece, pois os 
recursos se veem concentrados no caso visado. É considerado o método mais adequado para pesquisas exploratórias.

Já a técnica de coleta de dados foi por meio de entrevistas pessoais (questionário semiestruturado), observação nãoparticipante, que, segundo Godoy (1995), ocorre quando o pesquisador atua apenas como espectador atento, coletando dados e não participando do contexto no qual está inserido. $\mathrm{O}$ questionário semi-estruturado foi construído por questões abertas, previamente padronizadas, cujas respostas tomaram forma a partir do ponto de vista do entrevistado. A entrevista semi-estruturada é um dos instrumentos decisivos para estudar os processos e produtos nos quais está interessado o investigador.

\section{1 Coleta de Dados}

Com a finalidade de se atingir os objetivos propostos e responder ao problema de pesquisa, nove indivíduos de um mesmo grupo multifuncional foram entrevistados, sendo eles: um Gerente de Logística (GL) - de acordo com ele, sua área de atuação abrange toda a logística da empresa, da matéria-prima à entrega do produto acabado ao cliente; um Gerente de Manutenção (GM) - que havia sido gestor de produção e de engenharia; um Gerente Geral (GG) - que comanda a empresa e tem como responsabilidade traçar estratégias e responder junto ao diretor da empresa e à matriz nos Estados Unidos; e seis outros membros, entre estagiários, operadores de máquinas, líderes de produção etc.

A princípio buscou-se entrevistar também os gestores responsáveis pelo desenvolvimento de novos produtos, mas, durante duas visitas prévias e conversas formalizadas com membros da organização, um importante dado foi percebido - o de que a empresa não trabalhava necessariamente com inovação de produtos, mas com inovação de processos. A concepção do produto sempre é feita pelas montadoras (clientes), tornando-se um desafio para a organização gerar valor para esses clientes por meio de contínuo investimento em inovação de processos. A partir dessa informação, os autores do artigo decidiram entrevistar apenas os gestores vinculados diretamente ao processo como um todo e membros do grupo multifuncional, responsáveis pelo trabalho operacional. Entre visitas prévias, observação não participante, conversas formais e informais e entrevista com os gestores e membros do grupo multifuncional, somaram-se 10 horas de trabalho, gerando duas horas de gravações, além de anotações escritas. As entrevistas foram conduzidas individualmente em horários e dias diferentes nos meses de setembro e outubro de 2010, agendadas pelos próprios gestores, de acordo com a disponibilidade de cada um dos membros do grupo multifuncional. 


\section{RESULTADOS E DISCUSSÃO}

De acordo com as análises de conteúdo das entrevistas, o Autodesenvolvimento mostrou-se um importante fator capaz de promover a autonomia, tanto do grupo multifuncional, quanto de cada membro individualmente. Entretanto, no contexto deste trabalho, tal autonomia só foi percebida no momento em que os membros do grupo conduziam seus próprios cálculos estruturais e construíam protótipos, proporcionando o acúmulo de conhecimento. De forma limitada, a empresa conseguiu auxiliar a montadora no desenvolvimento do produto, mas não totalmente. Se comparado há três anos, por exemplo, houve grande avanço, pois tal poder autônomo não existia dentro da organização, senão apenas na matriz americana. Alcançar esse patamar de autonomia, mesmo que de forma limitada, foi crucial para $o$ desenvolvimento de processos inovadores.

A limitação de autonomia do grupo multifuncional analisado é percebida quando as principais tomadas de decisão cabem sempre ao coordenador da equipe. Conforme a fala do gerente de logística, "o coordenador nada mais é do que um maestro de uma orquestra, uma pessoa que dá a batida do evento".

Levando-se em consideração que a concepção do produto é imposta pelo cliente, é compreensível, então, o fato de não existir total autonomia nas tomadas de decisão sobre as tarefas, por exemplo. Por isso há a necessidade da existência de um coordenador que possa decidir e se responsabilizar pelos demais membros do grupo perante o cliente, pois tudo gira em torno das especificações estabelecidas pela montadora. Não cabe à empresa modificar o design da peça ou propor mudanças na etapa de desenvolvimento, pois o padrão já foi estabelecido com todas as características funcionais desejadas:

Resposta (GG): [...] "existe autonomia sim, mas é uma autonomia limitada e não ampla, ou seja, não se pode mudar, por exemplo, características funcionais e tarefas que estão inseridas nos processos. A gente não pode queimar etapas no desenvolvimento. O que é queimar etapas? É você fazer o desenvolvimento, mas não fazer as séries de ensaios de aprovação. Quando se vai ao cliente, deverá levar a peça desenvolvida e todos os ensaios já em mãos" [...].

Mas o mesmo pressuposto de Autodesenvolvimento emerge como um importante intento de Empoderamento, pois o compartilhamento de informações é feito por meio de uma política de interação entre operários, supervisores e $\mathrm{o}$ grupo multifuncional formado por membros de cada área da empresa. Isso acontece através de reuniões para determinar parâmetros definidos pelo grupo multifuncional, inclusive sobre necessidade de treinamentos.

Tais reuniões são denominadas de Walkabout e seu principal objetivo é permitir o acesso irrestrito à fábrica por todos os departamentos da empresa. Essa política gera uma redundância de informações, pois esse modelo de reuniões, além de ser diário, 
também é itinerante e está presente há mais de dez anos na empresa. Nele, alguns membros do grupo multifuncional pesquisado e de outros grupos organizacionais, possuem voz ativa ao compartilhar a realidade de sua equipe com a realidade de outros setores e com pessoas de vários níveis hierárquicos. De acordo com o gerente de logística, o Walkabout é uma ferramenta poderosa, desenvolvida para promover o Autodesenvolvimento de todas as pessoas por meio da prática da redundância das informações. Tanto metas quanto resultados emergidos no Walkabout são postos nos quadros de gestão à vista de cada setor visitado. Essas informações são compartilhadas e o constante reforço promove um fluxo de comunicação baseado na redundância entre a fábrica e os departamentos administrativos,

como compras, recursos humanos, engenharia etc.

No âmbito do grupo multifuncional, o Autodesenvolvimento acontece por meio da interação constante com vários substratos organizacionais, inclusive com outras equipes multifuncionais, através da sistematização de pequenos treinamentos semanais ou quinzenas. Conforme o gerente geral, o papel dos operários dentro do grupo multifuncional é fundamental, pois eles levam experiências vivenciadas na rotina dos processos produtivos pré-estabelecidos e sua visão sempre contribui para a formulação ou reformulação de novos processos.

Resposta (GL): [...] "cito, por exemplo, um grau de expertise do operador que influenciou diretamente na construção de uma ferramenta durante um treinamento. Existe uma peça nova que é muito parecida com uma que foi desenvolvida há alguns anos. Essa peça é em escala e tamanhos diferentes, não sendo igual à outra anterior. Mas esse operador, no processo de desenvolvimento da ferramenta de acabamento, sugeriu várias modificações e adequações que reduziu o tempo de setup, reduziu a quebra de ferramentas, facilitou a manutenção de ferramentas etc. Tudo isso utilizando da expertise do operador com tudo aquilo que ele tem vivência do dia a dia e que acaba repassando para os demais".

Além do Walkabout e dos treinamentos com o grupo multifuncional, mensalmente o diretor se reúne com o corpo operacional da empresa. Essa reunião tem como objetivo o repasse de informações sobre eventos que estejam acontecendo no âmbito financeiro, tecnológico, gerencial, de desempenho etc. Segundo o gerente geral, o nível de abrangência é de cem por cento em relação à população da fábrica, sendo o mais democrático possível. A partir desse total compartilhamento de informações estratégicas, é estabelecido novo levantamento de necessidade de treinamento (LNT), definido dentro de vários grupos, inclusive no grupo multifuncional analisado, com auxílio de um coordenador de treinamento e desenvolvimento (TD), que auxilia as equipes desde a determinação de aspectos relevantes ao cenário organizacional até problemas mais simples de ordem operacional.

O Autodesenvolvimento também pode ser observado quando o grupo multifuncional, 
ao enxergar uma necessidade em certa etapa da construção de uma peça, agrega mais pessoas à equipe por considerar que aquele determinado número de componentes não é o suficiente para a resolução de possíveis desafios advindos de novos processos. São pessoas com repertório interno maior, que ajudarão com seu conhecimento adquirido por meio de experiência de vida. Não são treinadores ou coachings, são membros que serão agregados ao grupo com a finalidade de enriquecê-lo. A agregação é realizada de forma sistemática, por meio de três ou quatro reuniões, até o estabelecimento de quais membros serão escolhidos. Depois dessa fase, todo o projeto é reapresentado ao grupo. Novamente são verificadas as fases daquilo que deverá ser desenvolvido, a forma de como será desenvolvido e os possíveis métodos de treinamento aos desafios encontrados.

Em relação à aprendizagem experencial, de acordo com o depoimento dos gestores, tal pressuposto foi verificado a partir da análise realizada sobre o produto da organização, que é fruto das tendências e necessidades internacionais, ou seja, produtos inovadores que estão sendo lançados nos principais mercados automotivos do mundo. O desafio da empresa é fazer aquilo que os gestores denominam "tropicalização" do produto, a fim de poder atender às necessidades do mercado brasileiro, o que sempre implica na aquisição de equipamentos diferenciados e novas tecnologias.
$\mathrm{Na}$ busca por adequações, a empresa consegue desenvolver inovações no processo de produção por meio da aquisição de novas tecnologias, pois o produto em si não tem como ser alterado, senão o seu modus operandi. Nos últimos dois anos, por exemplo, uma das tendências mais relevantes identificadas pela empresa será a substituição gradual do tipo de guarnições e vedações de borracha pelo plástico. Isso já é uma realidade em países industrializados. $\mathrm{Na}$ realidade brasileira, apenas algumas marcas de carros de luxo estão oferecendo tal inovação, mas a tendência existe e, a partir do momento em que a produção de vedações plásticas for maior que as de borracha, a economia de escala fará os custos reduzirem e tornar o mercado ainda mais competitivo.

De acordo com a visão do gerente geral, essa tendência se traduzirá numa grande inovação de processo, capaz de gerar mais valor para os clientes (montadoras), com forte impacto positivo para o meio ambiente, já que o plástico é muito mais reciclável que a borracha. Outras tendências podem ser observadas em eventos do setor e, de acordo com os entrevistados, os membros do grupo procuram acompanhá-las. Além da questão de gerar valor para o cliente por meio do desenvolvimento de processos, utilizando materiais com maior capacidade de reciclagem, existe também uma preocupação com a estética e a funcionalidade das peças automotivas. 
Na região asiática, por exemplo, uma tendência relevante é a substituição da alma metálica (fita de aço instalada na parte de dentro da guarnição) também pelo plástico, o que torna o produto esteticamente mais atrativo aos olhos do consumidor daquela região. Já para indústrias americanas, a grande preocupação é com a questão da funcionalidade da peça e não tanto com a estética.

Resposta (GG) [...] “os americanos são mais funcionais, enquanto os asiáticos se preocupam mais com o design da peça. Isso é uma tendência que nós temos que nos adequar e com isso, novas tecnologias são trazidas para o país para que sejam implantadas ao nosso processo". Nossa inovação é o processo de "tropicalização" dessas principais tendências internacionais do mercado.

Outro dado relevante em relação à aprendizagem é que, na atualidade, o grupo multifuncional pesquisado mantém alguns de seus membros em processo de constante interação entre as diversas plantas da empresa espalhadas pelo mundo - equivalente a oitenta fábricas - por meio de comunidade de prática.

O objetivo dessa interação é proporcionar ao grupo conhecimento de novas tecnologias desenvolvidas na França, Estados Unidos e, principalmente, na região da Ásia. Conforme a observação do gerente de logística, a produção de veículos no Brasil é fortemente influenciada pela indústria automobilística asiática, principalmente em relação aos modelos de produção japonesa e coreana. As necessidades do mercado brasileiro e, principalmente do internacional, fizeram com que fosse implantada uma política de institucionalização de aquisição de tecnologia de ponta. Com isso a empresa adquiriu softwares e demais equipamentos capazes de promover a construção de protótipos, atendendo melhor os clientes, proporcionando ganho de velocidade e desenvolvimento de processos inovadores. $\mathrm{Na}$ medida em que se consegue desenvolver novos processos, mais aprendizagem é acumulada, formando um círculo virtuoso envolvendo aquisição de tecnologia, inovação de processo, aumento do valor agregado do produto e ampliação da atuação mercadológica.

Outro dado interessante que surgiu durante as entrevistas foi o fato de haver um centro de desenvolvimento de produtos localizado na França. Conforme o gerente de manutenção, antigamente a empresa não dispunha de tal condição e essa evolução foi fruto de muito esforço organizacional. O mais importante é que alguns membros do grupo costumam visitar o centro de desenvolvimento regularmente, onde treinamentos são oferecidos. Eles aprendem as novidades e, ao voltarem para o Brasil, aplicam na realidade da planta brasileira. Se esse conhecimento não fosse compartilhado entre os demais indivíduos do grupo, a adequação ao processo e a geração de inovação seria muito lenta, incapaz de responder à velocidade mercadológica. 
Ainda sobre a aprendizagem experencial, dentro do grupo analisado, foi verificado que alguns operários considerados líderes informais, costumam participar de reuniões específicas de cunho estratégico com a cúpula da empresa. Os gestores entrevistados acreditam que a manutenção de um ambiente propício à inovação é a essência para a captação de novos clientes e a manutenção dos antigos, mas isso só será possível devido à participação de operários e líderes formais e informais de produção na construção de novos processos, possibilitando assim a geração de valor para as montadoras.

Resposta (GG): [...] “como no Brasil você faz inovações tecnológicas e adequação tecnológica, faz com que o cara que está com a mão na massa tenha uma visão diferenciada do engenheiro. Ou seja, o engenheiro ou quem está fazendo o desenvolvimento enxerga muito tecnicamente e o operador enxerga muito "praticamente". Então essa interação entre a experiência prática do operário acaba culminando num processo geralmente inovador, robusto, capaz e de baixo custo".

De acordo com o gerente geral, esse processo é denominado "melhoria contínua", por ser um ciclo. Por exemplo, um membro do grupo multifuncional, que também é operário e exerce influência nos seus iguais, ao estabelecer sua rotina própria, dependente ou não daquela repassada durante os treinamentos pelos engenheiros, completa um ciclo de aprendizagem e o conhecimento é internalizado. A partir desse momento esse operário começa a contribuir com sutis formas de aprimorar seu trabalho, fazendo-o melhor, com menor custo e menor tempo e ainda compartilhando com o grupo, conforme a afirmação do gerente de logística:

"Por exemplo, vamos pegar uma máquina que se você, ao regulá-la pela primeira vez irá fazer isso pelos padrões estabelecidos. Mas quando se faz esse mesmo processo pela segunda, quarta vez, você já regula baseado numa experiência e resultados anteriores que foram aprovados inclusive por aquele padrão. Então a experiência gera isso".

Em relação ao design do produto, pôde-se notar, pelo menos em relação aos operadores pertencentes ao grupo multifuncional pesquisado, que eles não participam da construção do desenho da peça. Assim como comentado anteriormente, eles têm uma função primordial no desenvolvimento de processos. O papel dos operários nessa fase é de ouvintes apenas, embora eles estejam presentes nesse tipo de reunião.

$\mathrm{O}$ gerente geral afirma que a participação do operador nas reuniões estratégicas com outros grupos multifuncionais é fruto de uma cultura organizacional ou parte da própria identidade da empresa. A tendência é que cada vez mais os operários possam contribuir efetivamente nos processos de tomada de decisão de âmbito estratégico, principalmente aquelas relacionadas à perda de contratos pelos concorrentes e à reclamação de clientes. Em relação a este último aspecto, além de ser abordado nas reuniões semanais, também é diariamente discutido, pois demanda uma velocidade muito maior para as decisões a serem tomadas. Por exemplo, quando acontece um problema específico com 
determinada peça e o cliente reclama, um alerta de qualidade é emitido e direcionado aos grupos que representam diretamente com aquele produto ou cliente, mas não para a fábrica inteira. Aquele grupo é informado do problema e a revisão das peças é feita. $\mathrm{O}$ grupo específico tem que tomar ciência o mais rápido possível, pois o cliente não pode esperar que o problema seja solucionado após um mês.

Resposta (GL): [...] "a função da qualidade é crucial, no nosso caso. Como a gente interage com todas as montadoras de veículos do país, acaba que cada cliente tem uma particularidade. Então a disseminação da informação com relação a isso fica bastante complicada, porque ela influencia bastante na próxima entrega" $[\ldots]$.

Outro aspecto verificado é que em qualquer das reuniões sistematizadas com os grupos multifuncionais, são informados detalhes sobre que o concorrente está fazendo: problemas de qualidade, perda de produção, entre outros. A empresa tem uma cultura aberta em relação às suas informações externas de âmbito estratégico. Inclusive é divulgado $o$ faturamento mensal $e$ rendimentos por operador.

\section{A Prática Reflexiva mostrou-se} também positiva no âmbito deste artigo. Por exemplo, o grupo multifuncional é estimulado para a quebra de rotinas e hábitos baseados em dois fatores principais: 1) seus membros são convidados para conhecer as principais novidades do setor, por meio de visitas aos clientes, participação em feiras nacionais e internacionais, visita ao centro de desenvolvimento de produto na França; 2) o grupo deve mudar constantemente sua abordagem em relação aos seus processos produtivos, pois trabalha tanto com pedidos de produção em massa, onde o processo deve ser mais robusto e com outra abordagem de produção em escala menor, menos densa.

Esse câmbio constante gera de certa forma, uma instabilidade interna, principalmente na agilidade dos setups. As adequações são constantes, principalmente porque o nível de exigência dos clientes muda de uma abordagem para outra.

Conforme o gerente de logística há quebra de paradigmas porque a conversão entre as duas abordagens de processo é seguida por diferentes demandas de conhecimento.

Embora o foco da pesquisa não tenha sido o setor de manutenção, ele também é um incentivador de reflexão por causar instabilidade interna, pois incentiva quebras de rotinas pré-estabelecidas. As intervenções são feitas, por exemplo, ao se questionar conceitos e definições institucionalizadas. A reflexão é promovida a respeito de métodos utilizados e a partir daí, surgem interações interpessoais - dentro do próprio grupo - e intergrupais, com o objetivo de tentar mudar a própria rotina dos departamentos. Nem sempre tal instabilidade traz ganhos pertinentes ao grupo multifuncional, mas a cultura de quebra de rotinas é reforçada, abrindo um leque para novas oportunidades, 
trazendo resultados interessantes. No mínimo proporciona que pessoas possam refletir e interagir com os demais departamentos. Sendo assim, novos desafios são postos ao ambiente de trabalho.

A empresa faz uso também de uma tecnologia de processos denominada things done right (TDR) e things done wrong (TDW), capazes de analisar e avaliar se as mudanças nos procedimentos se reverteram em aumento de valor agregado ou perda de eficiência. Assim a organização estabelece uma referência de aprendizagem na geração de conhecimento sobre mudanças de processos, ao mesmo tempo em que padroniza e quebra paradigmas, por meio de constante Prática Reflexiva.

\section{CONSIDERAÇÕES FINAIS}

$\mathrm{Na}$ presente pesquisa, pôde-se perceber como os pressupostos subjacentes ao Empoderamento podem ser positivos ao desenvolvimento de competências individuais e grupais sob o ponto de vista da criação de um ambiente favorável à inovação, principalmente quando analisado sob a óptica dos processos produtivos.

$\mathrm{O}$ fato de a empresa manter o grupo multifuncional em constante interação por meio de uma comunidade de prática com suas oitenta plantas espalhadas pelo mundo é, com certeza, uma política fundamental para o favorecimento de trocas de experiência e conhecimento, possibilitando a identificação de necessidades mercadológicas importantes.

O grupo se mostrou limitado quanto a aspectos referentes ao Autodesenvolvimento, principalmente naquelas atividades capazes de reforçar a autonomia da equipe em tarefas de desenvolvimento de produtos. Tal limitação se justifica pelo fato do produto vir pronto do cliente em termos de características inovadoras, bastando sua manufatura. Sendo assim, o desenvolvimento de novos produtos fica engessado pela montadora, não podendo servir de parâmetro ao processo de inovação na sua totalidade, mas sim como forma de processo inovador, ou a maneira de ser produzido, desde que entregue conforme especificações do cliente.

A gestão da organização mostrou-se aberta em introduzir um ambiente de mudanças constantes, que afetam diretamente na dinâmica grupal. Isso se confirma pelo fato da empresa incentivar a aprendizagem em relação ao modus operandi, que é posto constantemente em desafio pela simples meta de se produzir em massa ou de se produzir para mercados específicos, como em alguns países europeus, onde a produção de determinadas marcas de automóveis beira o nível artesanal. Ou seja, toda a rotina aprendida por meio de produção de massa é reaprendida quando a meta é produzir peças com características funcionais, bem como estéticas. 
As reuniões sistemáticas para o levantamento de necessidades de treinamento, principalmente o Walkabout, trazem grande contribuição para o reforço constante das informações da fábrica com o grupo analisado e sua interação redundante entre os setores fabris e administrativos.

Um aspecto importante é o fato do operador de máquinas, por exemplo, ter voz ativa, pois uma informação aprendida referente a problemas vivenciados por ele, contribui para a resolução de problemas relativamente comuns a outras linhas ou células de produção. Muito provavelmente o Walkabout seja o maior gerador de competências dentro da organização.

A Prática Reflexiva também se caracteriza como um aspecto imprescindível para a criação de novas competências entre os indivíduos e os grupos. A adequação tecnológica não poderia ser feita apenas pelo engenheiro. $\mathrm{O}$ operário, que lida com sua rotina diária, é capaz de visualizar nuances que não são percebidas pelos engenheiros. Em relação a esta questão (rotinas versus inovação), ainda é cedo para afirmar que a rotina pode ser uma geradora de inovação, mas no caso específico do presente trabalho, ela mostrou-se aliada ao surgimento de uma importante competência, que é a criação de processos inovadores a partir da reflexão do operário, que pode ser diferente da visão dos engenheiros.
De modo geral, dentro do grupo pesquisado, ambos os conceitos teóricos, racionalista e interpretativista, foram verificados. $\mathrm{O}$ ambiente empresarial ao qual a empresa está inserida é bastante competitivo. Muito provavelmente, se o grupo não possuísse atributos tais como, conhecimento adquirido por meio de treinamentos formais e experiência de vida, habilidade em dominar um terceiro idioma, condução de cálculos estruturais complexos, bem como habilidades em trabalhar em equipe e atitudes proativas, o processo de inovação não seria conquistado facilmente.

Ao mesmo tempo, nota-se que o processo de reflexão coloca em xeque constantemente todos esses atributos adquiridos por cada membro. Na realidade, o grupo se renova constantemente, novos indivíduos são inseridos, novos desafios surgem e tudo é reaprendido, num ciclo constante de renovação.

\section{REFERÊNCIAS}

CARBONE, P. P. et. al.Gestão por competências e gestão do conhecimento. Rio de Janeiro: FGV. 2006.

CONGER, J. A.; KANUNGO, R. N. "The Empowerment Process: Integrating Theory and Practice". Academy of Management Review, pp. 471-482, 1988.

DUTRA, J. S. (Org.) Gestão por

competências. São Paulo: Gente. 2001. 
FREIRE, P. Pedagogia da Esperança: um reencontro com a pedagogia do oprimido. Rio de Janeiro: Paz e Terra, 1992.

FULLAN, C; LANDO, A. R.; JOHANSEN, M.L.; REYES, A.; SZALOCZY D.M. The triad of empowerment: Leadership, environment, and professional traits. Nursing Economics; sep/oct 1998; 16, 5, Research Library.

GHAYE, T. Empowerment through reflection: competence for the new millennium or a case of the Emperor's new clothes. In: VELVE, C. (Org.). International perspectives on competence in the workplace: research, policy and practice. Kluwer Academic Publishers: Dordrecht/Boston/London, 2001.

GODOY, A. S. A pesquisa qualitativa: tipos fundamentais. Revista de Administração de Empresas, São Paulo, p. 20-29, maio/jun. 1995.

\section{KOLB, D. Experiential Learning:}

experience as the source of learning and development. New Jersey: Prentice Hall, 1984.

LAVILLE, C.; DIONE, J. A construção do saber. Belo Horizonte: UFMG, 1999.

LEI, D.; HITT, M.A. "Dynamic core competencies through meta-learning \& strategic context", Journal of Management, No. 4, p.549 - 561, 1996.

MINTZBERG, H. "An emerging strategy of "direct" research". Administrative Science, 1997, p. 582-589.

SPANGENBERG, H. H., SCHRODER, $\mathrm{H}$. M. e DUVENAGE, A.: "A leadership competence utilisation questionnaire for South African managers". South African Journal of Psychology, No. 3, p. 117 - 129, 1999.
SPREITZER, G. M. "Psychological Empowerment in Workplace: Construct Definition, Measurement and Validation". Academy of Management Journal, p. 14421465, 1995.

THOMAS, K. W.; VELTHOUSE, B. A. "Cognitive Elements of Empowerment: An "Interpretive" Model of Intrinsic Task Motivation", Academy of Management Review, No. 4, pp. 666-668, 1990. TRIVIÑOS, A. N. S. Introdução à Pesquisa em Ciências Sociais: a Pesquisa Qualitativa em Educação. São Paulo: Atlas, 1987. 